\title{
Effectiveness of Automated Connected Shuttles (ACS) During COVID-19 Pandemic
}

\author{
Shanjeeda Akter \\ Graduate Researcher, Department of Civil \\ Engineering \\ Kansas State University \\ Manhattan, KS, USA \\ shanjeeda@ksu.edu
}

\author{
HM Abdul Aziz, Ph.D. (Corresponding Author) \\ Assistant Professor, Department of Civil \\ Engineering \\ Kansas State University \\ Manhattan, KS, USA \\ ORCID: 0000-0002-8135-4577 \\ (azizhusain@ksu.edu)
}

\begin{abstract}
The COVID-19 pandemic had significantly impacted the public transit system in most cities across the world. Factors including physical distancing, remote working, distance education, and COVID-risk perception due to exposure have contributed to reducing public transport ridership. Automated Connected shuttles (ACS) services can be an effective alternative to regular buses with substantially reduced break-out risks and efficient operations. Our goal is to assess the mobility and energy impacts of ACS deployments when deployed as a replacement of standard (human-driven) buses within the context of the COVID-19 pandemic accounting for adjustment in passenger demand and capacity. To accomplish this purpose, we used a traffic microsimulation tool-PTV VISSIM-to simulate the behavior of buses and ACS units. We designed and simulated hypothetical scenarios in a New York City, NY, network. The scenarios are designed based on different COVID-19 restrictions, and the performances are compared to measure ACS effectiveness over regular buses. The results showed that ACS units are more effective than regular buses when they operate at business-asusual capacity. Further, ACS services are more energy-efficient during physical distancing restrictions than bus services based on the emissions and energy estimates using the EPA-MOVES tool.
\end{abstract}

\section{CCS CONCEPTS}

- Computing Methodologies • Applied Computing

\section{KEYWORDS}

Permission to make digital or hard copies of all or part of this work for personal or classroom use is granted without fee provided that copies are not made or distributed for profit or commercial advantage and that copies bear this notice and the full citation on the first page. Copyrights for components of this work owned by others than ACM must be honored. Abstracting with credit is permitted. To copy otherwise, or republish, to post on servers or to redistribute to lists, requires prior specific permission and/or a fee. Request permissions from Permissions@acm.org.

IWCTS'21, November 1, 2021, Beijing, China

(c) 2021 Association for Computing Machinery.

ACM ISBN 978-1-4503-9117-7/21/11

https://doi.org/10.1145/3486629.3490694
Autonomous Shuttle, COVID-19, Emissions, Environment, Transportation Energy, EPA-MOVES

\section{Motivation}

Nations worldwide are trying to combat the recent COVID-19 pandemic with consecutive lockdowns, physical distancing restrictions, and strict hygiene protocols. People have been staying home primarily either by choice or due to local

enforcements. As the pandemic progressed, it significantly impacted travel behavior-a shift towards private vehicles from the public transport modes to avoid a high risk of exposure to the virus. Several factors including, risk of infections, remote working, and fewer (educational, medical, and recreational) discretionary trips during the COVID-19 pandemic have significantly ( about $70-90$ percent) reduced public transport (PT) ridership in major cities, including New York City, NY, Washington DC, and San Francisco, CA [13] [38]. Moreover, transit agencies are burdened with disinfecting, personnel absences, growing labor costs while revenues are declining [3].

Thus, the COVID-19 crisis has put public transit-based mobility services into a survival mode. The public transit system faced hardship even before the pandemic-low ridership, farebox recovery, and service reliability. Transit authorities are putting their best efforts into improving the ventilation and hygiene inside buses and similar units. Nevertheless, it would be challenging to change the risk perception of the regular transit riders-is it safe to ride the buses? Studies [34] are already predicting a substantial shift toward personal mobility services. However, members from low-income and disadvantaged communities may not afford personal mobility services-own a car or use ride-hailing services. With low transit ridership and resulting fair-box revenues, it is possible that the transit service may be canceled or may only operate at a limited frequency. This will create a ripple effect putting more and more community members without any mobility services. 
Automated Connected Shuttles (ACSs) can play an essential role in reducing the exposure for both drivers and passengers during this current pandemic. Automated shuttles usually have a smaller capacity (4 - 16 passengers) compared to transit buses (a city transit bus can carry about $30-80$ passengers) and can operate over shorter routes with fewer stops. Also, the ACS units can run 24 hours a day and do not need human drivers. Thus, ACS services do not expect to struggle with driver shortage due to exposure to the virus and can be used in higher frequencies. Moreover, it is possible to assign designated shuttle services to carry elderly passengers with proper physical distancing. Therefore, it can be an alternative to standard transit services during the COVID-19 pandemic.

From the perspectives of traffic flow, the ACSs can have positive impact-the shorter headways of ACS units can significantly increase roadway and intersection capacity $[5,20]$. Conversely, if the regular buses were to be directly replaced with the ACS units, the traffic volume may increase because more ACS units will be needed to fill the capacity gaps compared with buses. Further, optimized ACS operations-routing and departure time-can reduce passenger waiting times [4,37]. Finally, electrified ACS services have the potential to cut down on-road fossil-fuel consumption and greenhouse gas (GHG) emissions from transportation networks. ACS services can be envisioned as an efficient and sustainable mobility solution for communities across the nation. The energy and emissions impacts will be dictated by the spatial-temporal distribution of the passenger demands, the charging infrastructure (static vs. dynamic charging), availability of distributed energy resources in the geographic area, and operational constraints. Now, these mobility and energy impacts are going to be different under the COVID-19 circumstancesphysical distancing, capacity reduction, and low demand.

This research aims to understand the effectiveness of ACS deployments by quantifying the network level mobility and energy impacts of ACS services when deployed as a replacement of standard (human-driven) buses within the context of the COVID-19 pandemic accounting for reduction passenger demand and capacity. The research questions are:

RQ-1: Would ACS units improve the traffic flow when deployed as replacements for buses under COVID-19 restrictions?

RQ-2: What is the impact of physical distancing restrictions on ACS services' performance (delay and travel time)?

RQ-3: Would ACS services reduce energy consumption and greenhouse gas emissions from transportation networks?

We evaluated the impact of ACS as a replacement of regular buses using traffic microsimulation-namely the PTV Vissim-to answer these questions.

\section{Literature Review}

Connected and automated vehicle (CAV) technology has gained popularity over the last decade because of its potential to improve traffic safety and mobility as well as energy efficiency. Several studies $[2,11,18,21]$ argued that CAVs will be more beneficial to the environment when used as public transportation services compared to personal mobility. Cities including Detroit, MI; Columbus, OH; Denver, CO; Las Vegas, NV had deployed pilots services in small areas for testing automated shuttles in the preCOVID-19 period to understand user perception and improve the automated shuttle [12,27]. The CityMobil project was a significant effort to integrate autonomous buses in different European cities [35]. Inspired by the success of the CityMobil project, the CityMobil2 project was set to explore the real-time interaction of autonomous buses with other road users in more realistic traffic conditions in European cities like Lausanne (Switzerland), Vantaa (Finland), Trikala (Greece), La Rochelle (France), and Oristano (Italy) [29,35]. During the COVID-19 era, some automated and connected shuttle projects have halted, while some of those have been repurposed to serve the community's needs. The AV shuttle program in Columbus, $\mathrm{OH}$, was set up to serve a small, underserved community. During the pandemic, that shuttle service is being used to deliver food in that community [9]. Orlando, FL, is using Automated shuttles in their community to transport COVID-19 tests and supplies at Mayo Clinic to reduce stress from healthcare resources and personnel [26].

Most existing studies on autonomous vehicles mainly focus on the effectiveness of passenger cars, while autonomous shuttles have been a less explored area [21]. The few studies on autonomous shuttles available in the literature are based on simulation and modeling approaches [19]. Researchers have developed models to replicate the behavior of ACS and compute their effects on the network. The Automated Mobility District-a concept proposed by the National Renewable Energy Laboratory-is a district-sized implementation of ACS service within a geofenced area [4]. This approach integrated a travel microsimulation model, energy estimation model and an optimization-based planning module for automated electric shuttle operation accounting for passenger waiting times using a mixed-integer program [4]. Hyland and Mahmassani [14] used sequential stochastic control and assignment to optimize fleets to reduce waiting times. An agentbased simulation study conducted to evaluate the performance of an integrated ACS-Public Transport system for Singapore which replaced $10 \%$ of low-demand first mile bus routes were ACS [30]. Results from this study showed that first and last mile ACS services were effective to reduce out-of-vehicle travel time while replacing only the first mile bus services with ACS worsened the system performance by increasing miles traveled [19,30]. Muhammad et al. [22] used a modified cellular automata model to investigate the impact of automated cars and buses on the traffic flow at different market penetration rates. Their results indicate that increasing the penetration rate of automated cars 
significantly improved the traffic flow and network speed while increasing the rate of autonomous buses increased the roadway capacity.

Many researchers sought shared autonomous vehicles (SAVs) as a potential alternative to mass transit. Levin et al. [17] developed a system optimal routing model for shared autonomous vehicles (SAVs) in 2017. Later in 2018, researchers explored the prospect of integrating SAVs with public transit [6]. In 2018, a simulation study for Berlin explored the potential of shared autonomous taxis as a replacement for buses. This study explored different capacity options and fleet sizes to serve the entire bus demand and found an SAV fleet size of 150 with a service capacity of 4 to be appropriate to meet the demand for the simulated area of 24,000 inhabitants [16].

ACS units can operate at a flexible schedule (routes and locations of stops) and adjust their capacity depending on passenger demands. Flexible scheduling may allow the ACS to serve the customers with a better reliability compared to regular buses and can result into to an increase in the ridership [7,8,21,23]. Studies also investigated the impacts of ACS schedule optimization on the network performance. Cao and Ceder [7] developed a mathematical model to optimize ACS schedules and found that skipping stops depending on real-time passenger demand distribution can improve passenger travel times and reduce ACS fleet size. This research also showed that advanced deficit function-based methodology has the potential to develop fully autonomous transit systems in a network in future [7]. Dai et al. [8] developed a mixed vehicle fleet environment comprised of human-driven buses and ACSs to optimize dispatching headways and capacity to improve the network's level of service and passenger waiting time. An integer nonlinear programming model was used to optimize the PT schedules and dispatch capacity jointly.

The above-mentioned discussion indicates that most studies are focused at business-as-usual cases and have not accounted for the cases where capacity and operational plans may be disrupted (such as the COVID-19 pandemic). Also, the energy and environmental impacts are not assessed except for a few studies. Our proposed research aims to address these gaps by answering the research questions (RQ 1 - RQ 3) posed in section 1.

\section{Experimental Design}

\subsection{Test Network}

Our test network is a $230 \mathrm{~m}$ roadway segment (Figure 1) of W Fordham Road in New York City, NY, from University Avenue to Davidson Avenue. Table 1 reports the geometric attributes of the network, and Figure 2 shows the exclusive bus lanes and the locations of curbside parking spaces. The W Fordham Road has two travel lanes on East-West approaches, excluding the bus lanes on both sides. The North-South approach is one way, and two lanes on both sides have on-street parking (Figure 1). At present, the road has a $10 \mathrm{ft}$ wide bus-only lane on both sides of the EastWest approach.

\subsection{Traffic Demand}

We have used the NYC open dataset (hourly volumes are available from October 31, 2015 to November 8, 2015) to determine the traffic demand for the test network. Evening Peak hours (6:00 7:00 pm) traffic volumes have been used to represent the congestion [24]. We have used average weekday traffic volumes to model the scenarios. Note that, the traffic volume for the test segment (Figure 1) is not directly available. Since the Grand Concourse to Valentine road section is within a single $\mathrm{km}$ stretch of our considered road segment, we have assumed that the traffic volume would remain unchanged from University Avenue to Valentine road segment. Further, the existing signal timing for the intersection has been extracted from the live video camera footage for an accurate representation of the scenario. Table 1 presents the traffic volumes used for this intersection.

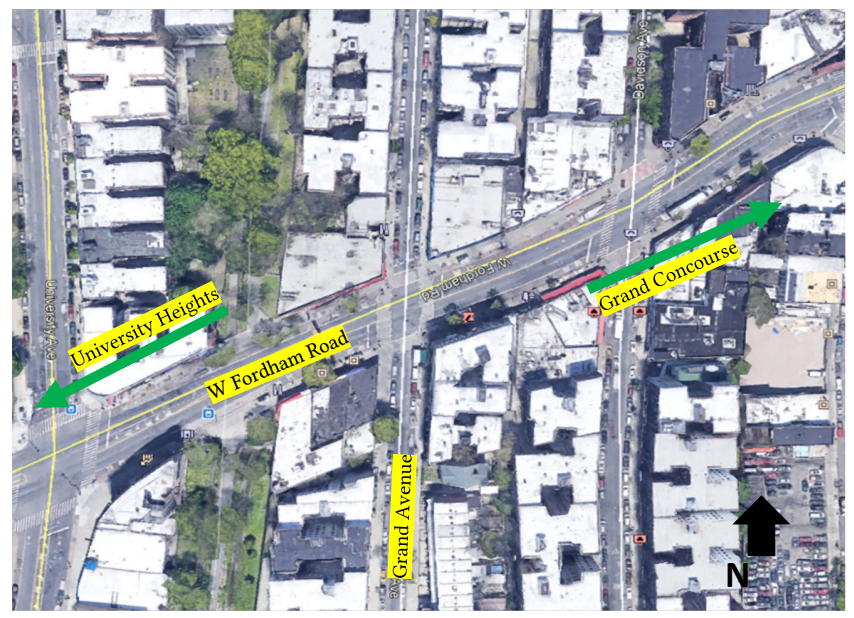

Figure 1: West Fordham Road, New York City, New York.

Table 1: Network Geometry for West Fordham Road

\begin{tabular}{|l|c|c|c|}
\hline Approach & $\begin{array}{l}\text { No. } \\
\text { of } \\
\text { Lanes }\end{array}$ & $\begin{array}{l}\text { Lane } \\
\text { Width } \\
\text { (ft) }\end{array}$ & $\begin{array}{l}\text { Peak Hour } \\
\text { Volume } \\
\text { (vehicles/hour) }\end{array}$ \\
\hline $\begin{array}{l}\text { Grand Concourse to } \\
\text { University Heights }\end{array}$ & 3 & 10 & 1050 \\
\hline $\begin{array}{l}\text { University Heights } \\
\text { to Grand Concourse }\end{array}$ & 3 & 10 & 850 \\
\hline Grand Avenue & 3 & 10 & 700 \\
\hline
\end{tabular}


Figure 2 shows the locations of bus lanes and bus stop modeled in this scenario. A bus stop is located at the beginning of the WestEast approach of Fordham Road. The scenario does not involve any transit signal priority. Four vehicle classes have been considered for the simulation: car, truck, delivery van, and bus. The proportions are chosen based on the NYC Open Data: 93\% car, $2 \%$ bus, $1 \%$ truck, and $4 \%$ delivery vans [25]. We assume the pedestrian activities do not affect the curbside operations near the intersection. We determined from the available vehicle composition that a total of 17 buses were operating in this street during the peak hour and assumed that the buses are running at an average occupancy (seating capacity at peak hour) of 31 passengers. We determined the bus demand be 510 passengers during peak hour with $210 \mathrm{~s}$ bus headway for our model using occupancy.

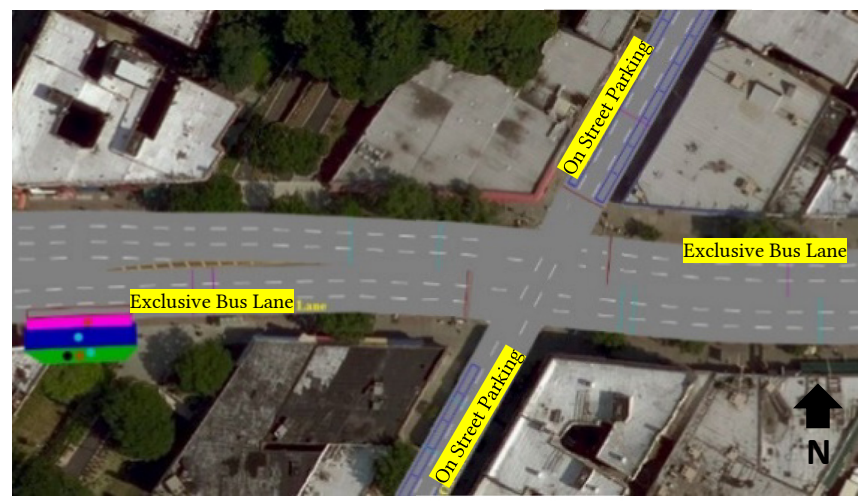

Figure 2: Exclusive Bus Lane on West Fordham Road (E-W Direction) and On-Street Parking on Grand Avenue (N-S Direction) (Snapshot from VISSIM)

\subsection{Scenario Descriptions (Bus vs. ACS Units Operations During COVID-19 Pandemic)}

During the COVID-19 pandemic, people worked from home or avoided bus rides due to the fear of infection. Accordingly, cities like New York City, NY; Seattle, WA; Chicago, IL, whose backbone is public transportation, faced significant reduction in ridership and fair-box revenue [15,33]. The subway ridership was down by around $92 \%$ in New York City, NY, in the beginning of the pandemic [15]. Later, city authorities enforced strict physical distancing in public transit services by reducing the passenger capacities. Likewise, New South Wales, Australia, imposed severe restrictions on public transport capacities by allowing a maximum of 12 passengers in $12 \mathrm{~m}$ long standard buses and 32 passengers in train carriages. In Asia, cities in China, Singapore reduced bus capacity by $50 \%$ [33]. Based on these observations, we designed three scenarios to evaluate within the PTV Vissim microsimulation framework.

To reflect the COVID-19 induced demand reduction, we considered a $50 \%$ decrease in the original demand (255 passengers) during peak hours while keeping all other traffic conditions constant. Also, the physical distancing requirements will dictate the passenger capacity and the required number of buses and ACS units to meet the demand. The specific scenarios are discussed below

Case A1 \& B1 (Low Ridership): Initially, we assume no physical distancing, only low ridership (expressed as average bus occupancy, no change in the passenger capacity) in the transit system. Case A1 and Case B1 in Table 2 represent the regular buses and ACS units, respectively that are operating at $100 \%$ capacity but have low demand.

Case A2, A3 \& B2 (Low Ridership and Enforced Physical Distancing): Next, we consider the case when physical distancing was enforced (either due to a higher COVID-19 positivity rate or as a preventive measure). The cases A2 and A3 represent the enforced physical distancing scenarios with two possible cases for the ACS units (50\% and $70 \%$ reduction in capacity, respectively) with the same level of demand. Case B2 reflects $30 \%$ reduction in capacity for buses, and this is based on observed data in some cities, and the relatively lower reduction compared to the ACS units is due to the joint effect of low bus ridership and space availability. A 16 passenger ACS unit may not have more than 8 passengers with physical distancing enforced whereas a 60-passenger capacity bus can go with 42-passenger capacity because of the higher space availability and ventilation.

When ACS services faces a $50 \%$ reduction in capacity, the number of ACS units needed to serve the same level of demand will be 32 (compared with 17 with full capacity). Now, when ACS units operate at $70 \%$ reduced capacity, 51 ACS units will be required to serve the same level of demand with a higher frequency. Table 2 describes the details of the scenarios.

Table 2: Scenario Description

\begin{tabular}{|c|c|c|c|c|}
\hline \multicolumn{5}{|c|}{ Regular Bus } \\
\hline 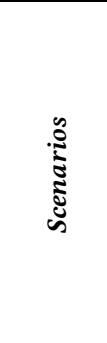 & 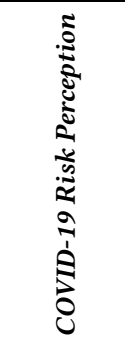 & 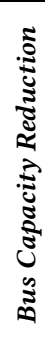 & 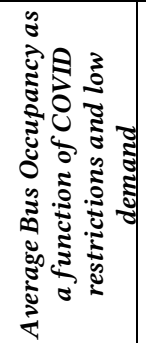 & 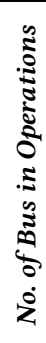 \\
\hline Case-B1 & $\begin{array}{c}\text { Mild \& No } \\
\text { Physical } \\
\text { Distancing }\end{array}$ & No & $\begin{array}{c}15(50 \% \\
\text { Demand } \\
\text { Reduction } \\
\text { from }\end{array}$ & 17 \\
\hline
\end{tabular}




\begin{tabular}{|c|c|c|c|c|}
\hline & & & $\begin{array}{c}\text { business- } \\
\text { as-usual) }\end{array}$ & \\
\hline Case-B2 & $\begin{array}{c}\text { Severe \& } \\
\text { Enforced } \\
\text { Physical } \\
\text { Distancing }\end{array}$ & $\begin{array}{c}\text { Yes (Buses } \\
\text { operating at } \\
30 \% \text { capacity } \\
\text { dictating the } \\
\text { occupancy) }\end{array}$ & 10 & 26 \\
\hline \multicolumn{5}{|c|}{ Automated Connected Shuttle (ACS) } \\
\hline 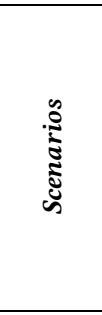 & 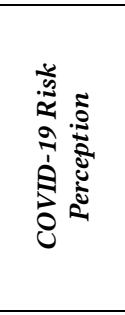 & 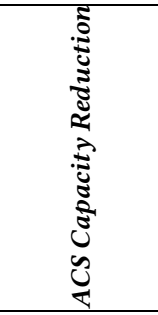 & 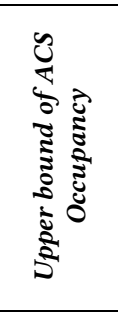 & 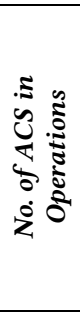 \\
\hline Case-A1 & $\begin{array}{l}\text { Mild \& No } \\
\text { Physical } \\
\text { Distancing }\end{array}$ & No & $\begin{array}{c}15(50 \% \\
\text { Demand } \\
\text { Reduction } \\
\text { from } \\
\text { business- } \\
\text { as-usual) }\end{array}$ & 17 \\
\hline Case-A2 & $\begin{array}{c}\text { Severe \& } \\
\text { Enforced } \\
\text { Physical } \\
\text { Distancing }\end{array}$ & $\begin{array}{c}\text { Yes (ACS units } \\
\text { operating at } \\
50 \% \text { capacity } \\
\text { dictating the } \\
\text { occupancy) } \\
\end{array}$ & 8 & 32 \\
\hline Case-A3 & $\begin{array}{c}\text { Severe \& } \\
\text { Enforced } \\
\text { Physical } \\
\text { Distancing }\end{array}$ & $\begin{array}{c}\text { Yes (ACS units } \\
\text { operating at } \\
30 \% \text { capacity } \\
\text { dictating the } \\
\text { occupancy) }\end{array}$ & 5 & 51 \\
\hline
\end{tabular}

\section{Modeling ACS Attributes in VISSIM}

To model the automation-specific car-following attributes of the automated connected shuttles (ACSs), we modified the carfollowing parameters in PTV VISSIM including desired speed, acceleration, and deceleration based on the following assumptions. (a) smaller standstill distance, safety distance, and shorter reaction time than human-driven vehicles, (b) minimal variation in the desired speed profile compared to human drivers, and (c) deterministic acceleration and deceleration rate and thresholds (AVs can maintain the exact prescribed values). These modifications are achieved by changing the Wiedeman'74 model [28], the car-following model in PTV VISSIM for urban arterial segments [31]. For human-driven vehicles, we have used the default parameters of driving behavior in the vehicle class-Urban (motorized). The autonomous attributes of the ACS units are described in a newly defined class-Urban-ACS. PTV VISSIM also accounts for the stochasticity of human drivers through predefined distributions. AVs have a shorter reaction time than human drivers $(0.5 \mathrm{~s})$ [36]. Also, automated vehicles will react to signals relatively faster, we have assumed an average reaction time to signal (e.g., $0.4 \mathrm{~s}$ ). A few parameters of ACS units used for simulation are presented in Table 3. We acknowledge that the chosen parameters are only a specific case for AV models and more research are required to understand the sensitivity of these parameters.
Table 3: Car-Following Parameters of ACS units

\begin{tabular}{|c|c|}
\hline $\begin{array}{c}\text { Wiedemann'74 car-following } \\
\text { parameters }\end{array}$ & Units (m) \\
\hline Average standstill distance & 1.00 \\
\hline Additive part of safety distance & 1.20 \\
\hline Reaction time distribution & Units (sec) \\
\hline Mean & 0.40 \\
\hline Std. dev & 0.01 \\
\hline Upper Bound & 0.50 \\
\hline Desired deceleration $\left(\mathrm{m} / \mathrm{s}^{2}\right)$ & -8.0 \\
\hline Maximum deceleration $\left(\mathrm{m} / \mathrm{s}^{2}\right)$ & -7.5 \\
\hline
\end{tabular}

Further, to capture the stochasticity in human driving, predefined Gaussian distributions are generally used for desired and maximum acceleration and deceleration values. In contrast, AVs are expected to behave with a lower variance (e.g., the desired speed is not expect to vary across different AVs unlike the human drivers) [36]. Therefore, we reduced the spread of maximum and minimum acceleration and deceleration values for ACS units [32].

Further, desired speed distribution is directly related to the capacity and travel times of links. The range of desired speed for human drivers will be wider compared with automated shuttles. Therefore, we have used desired speed distribution for conventional vehicles from $30 \mathrm{mph}$ to $35 \mathrm{mph}$. ACS are more likely to operate with a lower range as they will strictly follow the speed limits. We specified a new desired speed distribution for ACS with a value of $25 \mathrm{mph}$ because the implemented speed limit for ACS in most cities is lower than $25 \mathrm{mph}$ [39].

\section{Assessing Environmental and Energy Impacts}

To understand if the implementation of ACS will improve the environment, we have used EPA MOVES2014b and modeled emissions from different types of mobile sources. In the modeling process, specific fuel-based vehicle types, time periods, geographical area, pollutants, road types, and vehicle operational characteristics were used as input parameters. In addition to the above-mentioned inputs, emission-related information from EPA MOVES default database has been used. We have modeled passenger cars and trucks for gasoline-type fuel and commercial vehicles and transit buses for diesel-type fuels in this study. The analysis has been conducted for the peak hour $(6.00 \mathrm{pm}$ to 7.00 pm, November 2015). The analysis year has been selected to be 2015 as the traffic volume used for operational analysis is extracted from the year 2015. The network has 10 links and the link drive schedules have been computed from the first three simulation instances of VISSIM to use as an input for energy 
estimation. EPA MOVES has been used to compute energies for all classes of vehicles except the ACS units. Instead ACS specific energy are computed from the energy consumption graph developed for NAVYA automated shuttles [4]. The energy consumption rate graph is developed using data generated by the FASTSim energy modeling tool. Again, it is possible to assume other types of ACS specification. We chose NAVYA shuttle as our ACS unit representing vehicle due to availability of the energy consumption rate.

\section{Results and Discussions}

We simulate the scenarios described in the earlier sections in PTV VISSIM for $3600 \mathrm{~s}$ periods with different random seeds and collect data for the final $3000 \mathrm{~s}$ with delay section measurements and node evaluation metrics. We have three primary evaluation metrics for regular buses and ACS units:

(a) Average delay (all vehicles) (unit: seconds per vehicle unit): The experienced delay accounting for all classes and types of vehicles (transit modes and passenger cars, trucks and so on).

(b) Average delay (transit) (unit: seconds per vehicle): The experienced delay for the transit vehicles (e.g., only the ACS units when they replaced the buses and vice versa).

(c) Average person delay (transit) (unit: seconds per person): The experienced delay for each traveler using the transit mode-either bus (B1 and B2) or ACS units $(\mathrm{A} 1-\mathrm{A} 3)$

These evaluation metrics are compared with regular buses to understand the performance of ACS. For each performance metric, we estimated the range of population mean at $95 \%$ confidence level. Further, we conducted the Student's $t$-distribution tests since the variances are unknown.

The following sections will discuss the findings corresponding to our three research questions stated earlier.

RQ-1: Would ACS units improve transportation network performance when deployed as replacements for buses under COVID-19 restrictions?

Table 4 and Figure 3 show the comparison of performances between ACSs and regular buses. We consider cases where regular buses and ACS units operate at $100 \%$ capacity but face low ridership (represented by lower occupancy). Since the ACSs carry fewer passengers than buses, this reduction in average occupancy does not impact the ACS operations (flexibility regarding the number of ACS units to be deployed as a function of demand). Thus, the number of regular buses and ACS are identical in the network. The comparison shows that the average person delay reduces by $22.41 \%$ when ACSs are deployed in the network.
Average transit delay reduces by $21.69 \%$, while average delay for all vehicle classes reduces by $1.54 \%$. Even though the number of public transports is the same in both cases, the observed benefits of the ACSs may be due to uniform operations-less variation in speed and headways than standard bus operations. Also, the manual bus operation has higher headway. At the same time, the ACS units operate with smaller headways and strictly abide by the speed limit. This may have resulted in a lower delay for ACS units.

Table 4: Performance Metrics Comparison for Scenarios

\begin{tabular}{|c|c|c|c|c|}
\hline \multicolumn{5}{|c|}{ Case-B1 vs. Case-A1 (30 Simulation Runs) } \\
\hline & Regular Bu & $\begin{array}{c}\text { AV } \\
\text { Shuttle }\end{array}$ & $\begin{array}{l}\text { Improvement } \\
\text { Compared } \\
\text { with Transit } \\
\text { (Bus) Services }\end{array}$ & $\begin{array}{c}\text { Significance } \\
\text { at } 95 \% \\
\text { Confidence } \\
\text { Level }\end{array}$ \\
\hline \multicolumn{5}{|c|}{ Average Delay (All Vehicle) (sec/veh) } \\
\hline Mean & 27.10 & 26.68 & \multirow{3}{*}{$1.54 \%$} & \multirow{3}{*}{ Yes } \\
\hline $\begin{array}{l}\text { Upper } \\
\text { Bound }\end{array}$ & 27.30 & 26.92 & & \\
\hline $\begin{array}{l}\text { Lower } \\
\text { Bound }\end{array}$ & 26.90 & 26.45 & & \\
\hline \multicolumn{5}{|c|}{ Average Delay (Transit) (sec/veh) } \\
\hline Mean & 14.323119 & 11.216033 & \multirow{3}{*}{$21.69 \%$} & \multirow{3}{*}{ Yes } \\
\hline $\begin{array}{l}\text { Upper } \\
\text { Bound }\end{array}$ & 15.09 & 11.66 & & \\
\hline $\begin{array}{l}\text { Lower } \\
\text { Bound }\end{array}$ & 13.56 & 10.77 & & \\
\hline \multicolumn{5}{|c|}{ Average Person Delay (Transit) (sec/person) } \\
\hline Mean & 13.84 & 10.74 & \multirow{3}{*}{$22.41 \%$} & \multirow{3}{*}{ Yes } \\
\hline $\begin{array}{l}\text { Upper } \\
\text { Bound }\end{array}$ & 14.69 & 11.20 & & \\
\hline $\begin{array}{l}\text { Lower } \\
\text { Bound }\end{array}$ & 12.98 & 10.27 & & \\
\hline \multicolumn{5}{|c|}{ Case-B2 vs. Case-A2 (30 Simulation Runs) } \\
\hline & $\begin{array}{l}\text { Regular } \\
\text { Bus }\end{array}$ & AV Shuttle & Improvement & $\begin{array}{c}\text { Significance } \\
\text { at } 95 \% \\
\text { Confidence } \\
\text { Level }\end{array}$ \\
\hline \multicolumn{5}{|c|}{ Average Delay (All Vehicle) (sec/veh) } \\
\hline Mean & 26.93 & 26.95 & \multirow{3}{*}{$0.08 \%$} & \multirow{3}{*}{ No } \\
\hline $\begin{array}{l}\text { Upper } \\
\text { Bound }\end{array}$ & 27.1643 & 27.17 & & \\
\hline $\begin{array}{l}\text { Lower } \\
\text { Bound }\end{array}$ & 26.69 & 26.74 & & \\
\hline \multicolumn{5}{|c|}{ Average Delay (Bus) (sec/veh) } \\
\hline Mean & 14.88 & 13.62 & \multirow{3}{*}{$8.46 \%$} & \multirow{3}{*}{ Yes } \\
\hline $\begin{array}{l}\text { Upper } \\
\text { Bound }\end{array}$ & 15.34 & 14.05 & & \\
\hline $\begin{array}{l}\text { Lower } \\
\text { Bound }\end{array}$ & 14.42 & 13.19 & & \\
\hline \multicolumn{5}{|c|}{ Average Person Delay (Bus) (sec/person) } \\
\hline Mean & 13.81 & 12.68 & \multirow[b]{2}{*}{$8.14 \%$} & \multirow[b]{2}{*}{ Yes } \\
\hline $\begin{array}{l}\text { Upper } \\
\text { Bound }\end{array}$ & 14.42 & 13.14 & & \\
\hline
\end{tabular}




\begin{tabular}{|l|l|l|l|l|}
\hline $\begin{array}{l}\text { Lower } \\
\text { Bound }\end{array}$ & 13.19 & 12.24 & & \\
\hline
\end{tabular}

For B2 vs. A2, the physical distancing restrictions are enforced, and ACS units are impacted (passenger capacity goes down). For case A2, the number of ACS units deployed in the network is much higher than the regular buses (23\%). ACS service is operating at a lower capacity level since physical distancing restrictions have been applied. Hence, the average delay per person increases compared with Case-A1. However, the average delay person using ACS decreases significantly than the regular buses (case B2). The implementation of ACS will not significantly impact delay reduction for all other vehicles in the network; however, this will reduce overall delay for transit modes. This may be because of the existing exclusive bus lane, which omits the impact of increasing ACS volume on other vehicles of the network. Figure 3 summarizes the two comparisons.

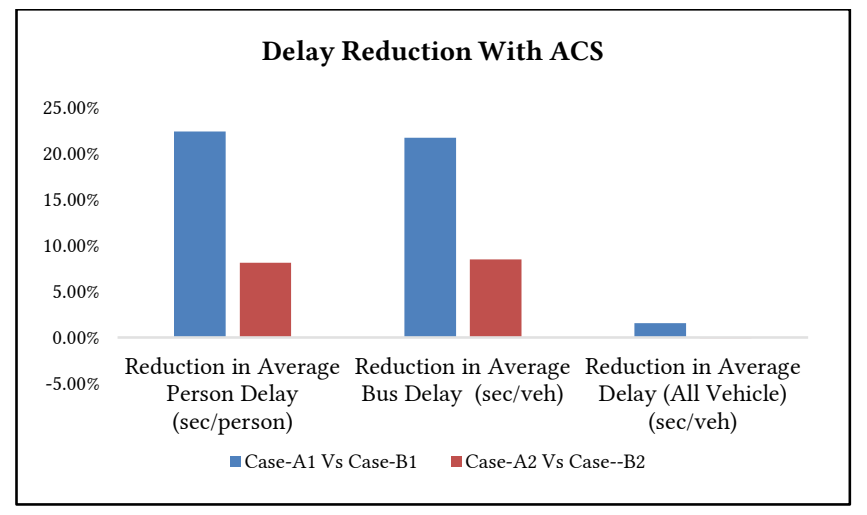

Figure 3: Reduction in Delay Due to ACS Implementation

RQ-2: What is the impact of physical distancing restrictions on ACS services' performance (delay and travel time)?

Table 5: Performance Metrics for ACS

\begin{tabular}{|c|c|c|c|}
\hline Scenarios & $\begin{array}{c}\text { Average } \\
\text { Delay (All } \\
\text { Vehicle) } \\
\text { (sec/veh) }\end{array}$ & $\begin{array}{c}\text { Average } \\
\text { Delay (ACS) } \\
\text { (sec/veh) }\end{array}$ & $\begin{array}{c}\text { Average } \\
\text { Person } \\
\text { Delay (ACS) } \\
\text { (sec/person) }\end{array}$ \\
\hline Case-A1 & 26.6839 & 11.216033 & 10.7397 \\
\hline Case-A2 & 26.9524 & 13.6231912 & 12.6861 \\
\hline Case-A3 & 26.7581 & 14.047558 & 13.7151 \\
\hline
\end{tabular}

Table 5 shows the performance of ACS at different capacity levels. When the number of ACS units is increased to 32 (Case-A2) from 17 (Case-A1), the average person delay goes up by $18 \%$, and it becomes $27 \%$ higher when the number of ACS is raised to 51 (Case-A3) by reducing the capacity to 5 persons per ACS unit. This may occur due to increased ACS volume in the exclusive bus lane. Since ACS units are operating at a lower capacity (Case-A2 and A3), people are waiting for a longer time to reach their destination; thus, the average person delay is increasing. The average delay for ACS goes up by about $21 \%$ and $35 \%$ for incrementing ACS by 15 (Case-A2) and 34 (Case-A3) units, respectively. So, it can be concluded that imposing physical restrictions will increase passenger and vehicle travel time for the same level of passenger demand since the passenger-carrying capacity for the ACS is being cut off.

RQ-3: Would ACS services reduce energy consumption and the greenhouse gas emissions from transportation networks?

Figure 4 summarizes the change in the energy consumption and emissions after the implementation of ACS services. If we compare the energy consumption for ACS and regular buses, it can be observed that, total energy consumption decreases by $2.32 \%$ (Case-A1 vs. Case B1) when ACS are deployed indicating that ACS units are energy efficient than the regular buses. Figure 4 also shows that, the total $\mathrm{CO}$ emissions can be reduced by $2.23 \%$ (Case-A1 vs. Case B1) by ACS units. By implementing ACS, the primary exhaust from vehicles (PM 2.5 and PM 10) in the network can be reduced by about $34 \%, \mathrm{CO}_{2}$ emission can be reduced by about $3 \%$ and emission of $\mathrm{NO}_{\mathrm{x}}$ gases can be reduced by about $46 \%$ (Case-A1 Vs Case B1). The detailed results of the energy consumption and emission are provided in Table 6.

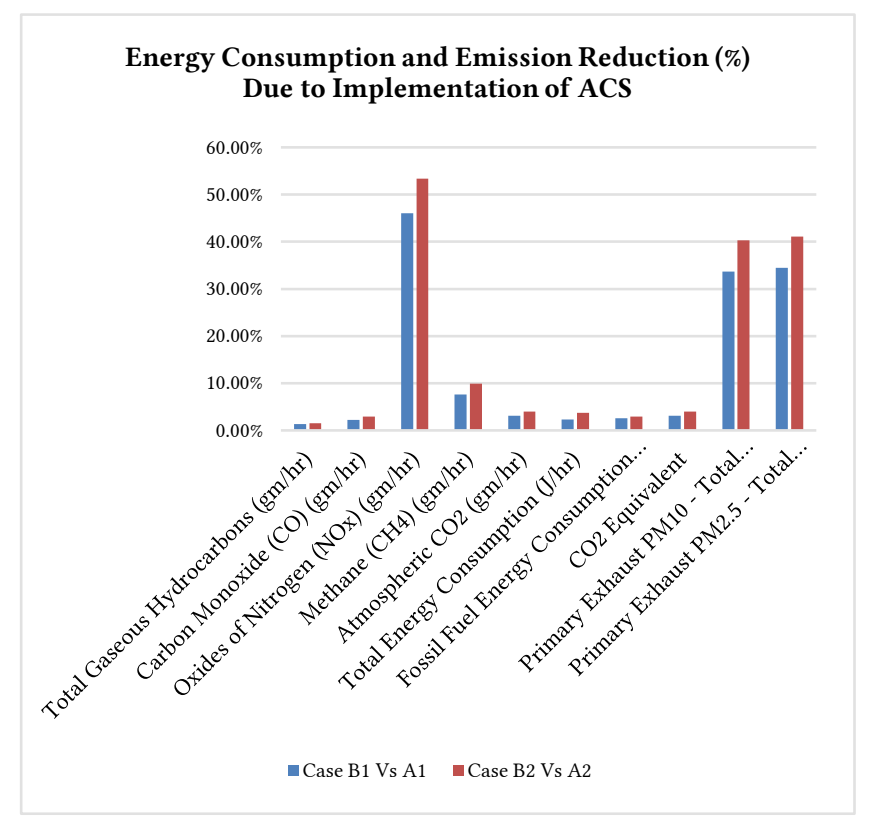

Figure 4: Change in Energy Consumption and Emission for ACS Implementation 
Table 6: Comparison of Energy Consumption and Emission

\begin{tabular}{|l|c|c|c|}
\hline \multicolumn{4}{|c|}{ Case-A1 vs. Case B1 (Average from three simulation runs) } \\
\hline Pollutants & Case-B1 & Case-A1 & $\begin{array}{c}\text { Improvem } \\
\text { ent }\end{array}$ \\
\hline $\begin{array}{l}\text { Total Gaseous } \\
\text { Hydrocarbons (gm/hr) }\end{array}$ & 734.27 & 724.43 & $1.34 \%$ \\
\hline $\begin{array}{l}\text { Carbon Monoxide (CO) } \\
\text { (gm/hr) }\end{array}$ & 1606.27 & 1570.40 & $2.23 \%$ \\
\hline $\begin{array}{l}\text { Oxides of Nitrogen } \\
\text { (NOx) (gm/hr) }\end{array}$ & 251.68 & 135.84 & $46.03 \%$ \\
\hline Methane (CH4) (gm/hr) & 4.07 & 3.75 & $7.64 \%$ \\
\hline Atmospheric CO2 (kg/hr) & 343.09 & 332.53 & $3.08 \%$ \\
\hline $\begin{array}{l}\text { Total Energy } \\
\text { Consumption (GJ/hr) }\end{array}$ & 4769.62 & 4659.13 & $2.32 \%$ \\
\hline $\begin{array}{l}\text { Fossil Fuel Energy } \\
\text { Consumption (GJ/hr) }\end{array}$ & 4460.71 & 4345.10 & $2.59 \%$ \\
\hline CO2 Equivalent (kg/hr) & 343.19 & 332.62 & $3.08 \%$ \\
\hline $\begin{array}{l}\text { Primary Exhaust PM10 - } \\
\text { Total (gm/hr) }\end{array}$ & 12.15 & 8.06 & $33.64 \%$ \\
\hline $\begin{array}{l}\text { Primary Exhaust PM2.5 - } \\
\text { Total (gm/hr) }\end{array}$ & 10.93 & 7.16 & $34.43 \%$ \\
\hline \multicolumn{1}{|c|}{ Case-A2 vs. Case-B2 (Average from three simulation runs) } \\
\hline Pollutants & Case-B2 & Case-A2 & Improvem \\
ent
\end{tabular}

Our experimental results indicate that if ACS units are deployed at their total capacity to carry the same number of passengers when regular buses face low ridership, and there are no travel restrictions, it can improve user travel quality with less impact on the environment and save energy. When physical restrictions are applied, ACS will still be economical to save energy and improve transit performance in the network. However, for low passenger carrying capacity, passengers may experience higher delays compared to bus-only services.

\section{Conclusions}

The COVID-19 pandemic took its toll on the transportation industry by reducing transit ridership and the travelers' associated hardships-accessibility and mobility. People shifted towards other modes of transport from buses to avoid exposure. Automated connected shuttles (ACS) can be a viable alternative to reduce the risks of exposure and the operating costs of public transports. In this paper, we have evaluated the effectiveness of ACS compared to regular public transports in terms of energysaving and delay reduction. This research shows that when bus ridership drops for the pandemic, ACS services can significantly improve travel quality and network performance (case B1 vs. case A1). However, the person delay increases significantly for ACS units (A2 and A3) with the capacity constraint imposed by the physical distancing.

ACS services are also an effective strategy to reduce energy consumption and emission of greenhouse gases (GHG). When physical restrictions are applied to both the regular buses and ACS, the difference between their performances reduces. The trend is the same for both per capita fuel and $\mathrm{CO}$ emissions from our experimental results.

\subsection{Limitations}

We have not calibrated the network for this research and have used simulation parameters available in the existing literature. Calibrating the network for a mixed environment could lead to new observations for the efficiency of ACS at the network level. For the experiments conducted in this research, the standing capacity of buses has not been used, which can be included in future research. For future research, the interactions of vehicles with roadside activities can be included in the model. This research can be beneficial to practitioners and policymakers to understand how ACS will work in the post-pandemic situation when public transit ridership may get back to the pre-COVID demand.

\subsection{Future Directions}

Emerging mobility services, including ride-hailing or ridesourcing (sometimes argued as a competitor to the transit systems) and micro-mobility travel modes (bike-sharing, escooters, micro-transit), can be a part of the solution, provided that cooperation and coordination with transit systems can be achieved. This study was conducted on a small part of the city which can further be extended to city-wide analysis to understand the applicability of the policies on a bigger scale. Our proposed solution may assist in developing a community-shared micro- 
transit-based mobility system that ensures physical distancing and is less crowded than standard bus services, provides flexibility (route and frequency), and enables automated contact tracing. The proposed service need not necessarily replace the existing transit system. As COVID-19 situations evolve, the robust mobility system can replace the entire system temporarily or simply complement a part of it as needed.

\section{REFERENCES}

[1] Hafiz Usman Ahmed, Ying Huang, and Pan Lu. 2021. A Review of CarFollowing Models and Modeling Tools for Human and AutonomousReady Driving Behaviors in Micro-Simulation. Smart Cities 4, 1 (March 2021), 314-335. DOI:https://doi.org/10.3390/SMARTCITIES4010019

[2] Jaagup Ainsalu, Ville Arffman, Mauro Bellone, Maximilian Ellner, Taina Haapamäki, Noora Haavisto, Ebba Josefson, Azat Ismailogullari, Bob Lee, Olav Madland, Raitis Madžulis, Jaanus Müür, Sami Mäkinen, Ville Nousiainen, Eetu Pilli-Sihvola, Eetu Rutanen, Sami Sahala, Boris Schønfeldt, Piotr Marek Smolnicki, Ralf-Martin Soe, Juha Sääski, Magdalena Szymańska, Ingar Vaskinn, and Milla Åman. 2018. State of the Art of Automated Buses. Sustain. 2018, Vol. 10, Page 3118 10, 9 (August 2018), 3118. DOI:https://doi.org/10.3390/SU10093118

[3] American Public Transportation Association. 2021. Impact of COVID-19 Pandemic on Public Transit Funding Needs.

[4] H. M.Abdul Aziz, Venu Garikapati, Tony K. Rodriguez, Lei Zhu, Bingrong Sun, Stanley E. Young, and Yuche Chen. 2020. An optimization-based planning tool for on-demand mobility service operations. Int. 7. Sustain. Transp. 0, 0 (2020), 1-12. DOI:https://doi.org/10.1080/15568318.2020.1847368

[5] H.M.A. Aziz. 2019. Energy and Mobility Impacts of System Optimal Dynamic Traffic Assignment for a Mixed Traffic of Legacy and Automated Vehicles. DOI:https://doi.org/10.1177/0361198119845658

[6] Rounaq Basu, Andrea Araldo, Arun Prakash Akkinepally, Bat Hen Nahmias Biran, Kalaki Basak, Ravi Seshadri, Neeraj Deshmukh, Nishant Kumar, Carlos Lima Azevedo, and Moshe Ben-Akiva. 2018. Automated Mobility-on-Demand vs. Mass Transit: A Multi-Modal Activity-Driven Agent-Based Simulation Approach. Transp. Res. Rec. 2672, 8 (December 2018), 608-618. DOI:https://doi.org/10.1177/0361198118758630

[7] Zhichao Cao and Avishai (Avi) Ceder. 2019. Autonomous shuttle bus service timetabling and vehicle scheduling using skip-stop tactic. Transp. Res. Part C Emerg. Technol. 102, (May 2019), 370-395.

DOI:https://doi.org/10.1016/J.TRC.2019.03.018

[8] Zhuang Dai, Xiaoyue Cathy Liu, Xi Chen, and Xiaolei Ma. 2020. Joint optimization of scheduling and capacity for mixed traffic with autonomous and human-driven buses: A dynamic programming approach. Transp. Res. Part C Emerg. Technol. 114, March (May 2020), 598-619. DOI:https://doi.org/10.1016/j.trc.2020.03.001

[9] Skip Descant. 2021. Self-Driving Shuttles Find New Uses During Pandemic.

[10] Alastair Evanson. 2017. CONNECTED AUTONOMOUS VEHICLE (CAV) SIMULATION USING PTV VISSIM. In Proceedings of the 2017 Winter Simulation Conference.

[11] Eva Fraedrich, Dirk Heinrichs, Francisco J. Bahamonde-Birke, and Rita Cyganski. 2019. Autonomous driving, the built environment and policy implications. Transp. Res. Part A Policy Pract. 122, (April 2019), 162-172. DOI:https://doi.org/10.1016/J.TRA.2018.02.018

[12] Antora Mohsena Haque and Candace Brakewood. 2020. A synthesis and comparison of American automated shuttle pilot projects. Case Stud. Transp. Policy 8, 3 (September 2020), 928-937. DOI:https://doi.org/10.1016/J.CSTP.2020.05.005

[13] Saskia Hausler, Kersten Heineke, Russell Hensley, Timo Möller, Dennis Schwedhelm, and Pei Shen. 2020. The impact of COVID-19 on future mobility solutions.

[14] Michael Hyland and Hani S. Mahmassani. 2018. Dynamic autonomous vehicle fleet operations: Optimization-based strategies to assign AVs to immediate traveler demand requests. Transp. Res. Part C Emerg. Technol. 92, April (2018), 278-297. DOI:https://doi.org/10.1016/j.trc.2018.05.003

[15] Alejandro De La Garza. 2021. COVID-19 Has Been "Apocalyptic" for Public Transit | Time.

[16] Gregor Leich and Joschka Bischoff. 2019. Should autonomous shared taxis replace buses? A simulation study. Transp. Res. Procedia 41, (January 2019), 450-460. DOI:https://doi.org/10.1016/J.TRPRO.2019.09.076

[17] Michael W. Levin, Kara M. Kockelman, Stephen D. Boyles, and Tianxin
Li. 2017. A general framework for modeling shared autonomous vehicles with dynamic network-loading and dynamic ride-sharing application. Comput. Environ. Urban Syst. 64, (2017), 373-383. DOI:https://doi.org/10.1016/j.compenvurbsys.2017.04.006

[18] Todd Litman. 2014. Autonomous Vehicle Implementation Predictions: Implications for Transport Planning. Transp. Res. Board Annu. Meet. 42, 2014 (2014), 36-42. DOI:https://doi.org/10.1613/jair.301

[19] Mahmood Mahmoodi Nesheli, Lisa Li, Matthew Palm, and Amer Shalaby. 2021. Driverless shuttle pilots: Lessons for automated transit technology deployment. Case Stud. Transp. Policy 9, 2 (June 2021), 723742. DOI:https://doi.org/10.1016/J.CSTP.2021.03.010

[20] Mark Mario Morando, Oingyun Tian, Long T. Truong, and Hai L. Vu. 2018. Studying the Safety Impact of Autonomous Vehicles Using Simulation-Based Surrogate Safety Measures. F. Adv. Transp. 2018, (April 2018). DOI:https://doi.org/10.1155/2018/6135183

[21] Kostas Mouratidis and Victoria Cobeña Serrano. 2021. Autonomous buses: Intentions to use, passenger experiences, and suggestions for improvement. Transp. Res. Part F Traffic Psychol. Behav. 76, (January 2021), 321-335. DOI:https://doi.org/10.1016/J.TRF.2020.12.007

[22] Tanveer Muhammad, Faizan Ahmad Kashmiri, Hassan Naeem, Xin Qi Hsu Chia-Chun, and Huapu Lu. 2020. Simulation Study of Autonomous Vehicles' Effect on Traffic Flow Characteristics including Autonomous Buses. 7. Adv. Transp. 2020, (2020). DOI:https://doi.org/10.1155/2020/4318652

[23] Vibeke Nenseth, Alice Ciccone, and Niels Buus Kristensen. 2019. Societa consequences of automated vehicles - Norwegian scenarios.

[24] NYC OpenData. 2020. Traffic Volume Counts (2014-2019). NYC Department of Transportation (DOT).

[25] NYC OpenData. 2020. Vehicle Classification Counts (2014-2019). NYC Department of Transportation (DOT).

[26] Sean O'Kane. Supervised self-driving shuttles are moving COVID-19 tests in Florida - The Verge. 2020.

[27] Kelsey Oldbury and Karolina Isaksson. 2021. Governance arrangements shaping driverless shuttles in public transport: The case of Barkarbystaden, Stockholm. Cities 113, (June 2021), 103146 DOI:https://doi.org/10.1016/J.CITIES.2021.103146

[28] PTV. 2021. PTV VISSIM 2021 User Manual. (2021)

[29] Anna Schieben, Marc Wilbrink, Carmen Kettwich, Ruth Madigan, Tyron Louw, and Natasha Merat. 2018. Designing the interaction of automated vehicles with other traffic participants: design considerations based on human needs and expectations. Cogn. Technol. Work 21, 1 (September 2018), 69-85. DOI:https://doi.org/10.1007/S10111-018-0521-Z

[30] Yu Shen, Hongmou Zhang, and Jinhua Zhao. 2018. Integrating shared autonomous vehicle in public transportation system: A supply-side simulation of the first-mile service in Singapore. Transp. Res. Part A Policy Pract. 113, April (2018), 125-136. DOI:https://doi.org/10.1016/j.tra.2018.04.004

[31] Maryland DOT State Highway Administration. 2017. VISSIM Modeling Guidance.

[32] Peter Sukennik. 18AD. Micro-simulation guide for automated vehicles.

[33] Alejandro Tirachini and Oded Cats. 2020. COVID-19 and public transportation: Current assessment, prospects, and research needs. $\mathcal{F}$. Public Transp. 22, 1 (2020), 1-34. DOI:https://doi.org/10.5038/23750901.22.1.1

[34] Alejandro Tirachini and Oded Cats. 2020. COVID-19 and Public Transportation: Current Assessment, Prospects, and Research Needs. 7 . Public Transp. 22, 1 (January 2020), 1-34. DOI:https://doi.org/10.5038/2375-0901.22.1.1

[35] S. Tsigdinos, C. Karolemeas, E. Bakogiannis, and A. Nikitas. 2021 Introducing autonomous buses into street functional classification systems: An exploratory spatial approach. Case Stud. Transp. Policy 9, 2 (June 2021), 813-822. DOI:https://doi.org/10.1016/J.CSTP.2021.03.018 Desmond Yuen. 2021. Making Roads Safer with Self-Driving Cars and $5 \mathrm{G}$.

[37] Lei Zhu, Venu Garikapati, Yuche Chen, Yi Hou, H. M.Abdul Aziz, and Stanley Young. 2018. Quantifying the mobility and energy benefits of automated mobility districts using microscopic traffic simulation. Int. Conf. Transp. Dev. 2018 Connect. Auton. Veh. Transp. Saf. - Sel. Pap. from Int. Conf. Transp. Dev. 2018 (2018), 98-108. DOI:https://doi.org/10.1061/9780784481530.010

[38] Impact of COVID-19 on Adoption of Autonomous Vehicle Technology. [39] Self-Driving Shuttle for Passenger Transportation - NAVYA. 